\title{
Genetic relatedness of Brazilian Colletotrichum truncatum isolates assessed by vegetative compatibility groups and RAPD analysis
}

\author{
JULIANE R SANT'ANNA ${ }^{1} *$, CLÁUDIA T MIYAMOTO ${ }^{1} *$, LUCIA J ROSADA $^{1}$, \\ CLAUDINÉIA C S FRANCO ${ }^{1}$, EDILSON N KANESHIMA ${ }^{2}$ \\ and MARIALBA A A CASTRO-PRADO ${ }^{1 * *}$
}

Universidade Estadual de Maringá.

${ }^{1}$ Departamento de Biologia Celular e Genética.

${ }^{2}$ Departamento de Análises Clínicas. Avenida Colombo 5790. Maringá, PR 87020-900, Brasil.

\begin{abstract}
The genetic variation among nine soybean-originating isolates of Colletotrichum truncatum from different Brazilian states was studied. Nitrate non-utilizing (nit) mutants were obtained with potassium chlorate and used to characterize vegetative compatibility reactions, heterokaryosis and RAPD profile. Based on pairings of nit mutants from the different isolates, five vegetative complementation groups (VCG) were identified, and barriers to the formation of heterokaryons were observed among isolates derived from the same geographic area. No complementation was observed among any of the nit mutants recovered from the isolate A, which was designed heterokaryon-self-incompatible. Based on RAPD analysis, a polymorphism was detected among the wild isolate $\mathrm{C}$ and their nit1 and NitM mutants. RAPD amplification, with five different primers, also showed polymorphic profiles among Brazilian $C$. truncatum isolates. Dendrogram analysis resulted in a similarity degree ranging between 0.331 and 0.882 among isolates and identified three RAPD groups. Despite the lack of a correlation between the RAPD analysis and the vegetative compatibility grouping, results demonstrated the potential of VCG analysis to differentiate $C$. truncatum isolates genotypically similar when compared by RAPD.
\end{abstract}

Key terms: genetic variability, heterokaryosis, parasexual recombination, RAPD.

\section{INTRODUCTION}

Anthracnose is one of the most destructive fungal diseases of soybean (Glycine max) causing considerable losses in soybeangrowing regions worldwide, especially when warm and humid conditions exist, favoring pathogen development. The disease reduces stand, seed quality and yields. In certain Brazilian regions anthracnose is one of the most important phytosanitary factors causing total soybean yield losses. Anthracnose affects all aboveground parts of the vegetable soybean and the typical symptoms, characterized by brown and irregularly shaped spots, appear during early reproductive stages on stems, pods and petioles. Although seedling infections may occur, anthracnose may also attack more mature plants during the latter part of the growing season (Almeida et al., 2005; Chen et al., 2006).

The most common pathogen associated with soybean anthracnose is the filamentous fungus Colletotrichum truncatum (Schwein.) Andrus \& W. D. Moore, (teleomorphic Glomerella truncata C.L. Armstr. \& Banniza), belonging to the class of Pyrenomycetes. This class includes many species of Colletotrichum causing anthracnose in a wide range of crops, such as lentils (Lens culinaris), fababeans (Vicia

\footnotetext{
* These authors contributed equally to this work.

** Corresponding Author: M. A. A. Castro-Prado, Phone: (+55) 443261 4679, Fax: (+55) 443261 4893, E-mail: maacprado@uem.br.
} 
faba) and peas (Pisum sativum), and even in ornamental plant species (Freeman et al., 2000; Curry and Baird, 2004).

Isolates of $C$. truncatum vary considerably in colony characteristics, size of fruiting structures and pathogenicity. Additionally, $C$. truncatum from different hosts often exhibit different host preferences. Previous studies have demonstrated that $C$. truncatum isolates from lentils and peas infected and sporuled on both hosts, but were unable to infect soybean (Weidemann et al., 1988; Anderson et al., 2000). On the other hand, isolates from hemp sesbania (Sesbania exaltata) were specific to that host (Boyette, 1991).

RAPD markers and rDNA sequence data have been utilized to assess the genetic variability of $C$. truncatum isolates infecting lentils, soybeans, Xanthium sp. and peanuts. Results have shown the genetic relatedness of $C$. truncatum isolates from the same host species and discriminated among isolates from lentils and other host species (Ford et al., 2004). The high degree of genetic variability of fifty-eight $C$. truncatum isolates from urdbean, horsegram, soybean, ricebean, cowpea and mungbean, collected from the northwestern Himalayas, was also demonstrated by RAPD profiles generated by random primers (Sharma, 2007).

Processes of gene mutation, heterokaryosis and mitotic recombination have been proposed to explain the high pathogenic variability of several Colletotrichum species (Casela and Frederiksen, 1994; Chacko et al., 1994; Souza-Paccola et al., 2003). The parasexual process has in fact been considered as a possible mechanism for genetic diversity among asexual and phytopathogenic fungi (Caten, 1981; Zeigler et al., 1997). Heterokaryosis, the association of two genetically different nuclei in a common cytoplasm, and asexual gene exchange, however, are limited by vegetative compatibility loci named het (for heterokaryon incompatibility) or vic (for vegetative incompatibility), so that only compatible strains, genetically similar to vic or het genes, may produce stable heterokaryons among themselves. Such compatible strains are classified as members of the same vegetative compatibility group (VCG) (Leslie, 1993; Busso et al., 2007).

The aims of the current research were to estimate the genetic variability among soybean-originating $C$. truncatum isolates from different Brazilian states, and to assess the diversity of vegetative compatibility reactions among them for a subsequent analysis of the potential for asexual gene exchange in $C$. truncatum isolates.

\section{MATERIAL AND METHODS}

\section{Fungal isolates and media}

Nine soybean isolates of $C$. truncatum were employed in this study. Isolates A to D were kindly donated by Dr. William Mário de Carvalho Nunes (Departamento de Agronomia, Universidade Estadual de Maringá, Paraná, Brazil), while isolates E to I were obtained from Embrapa Soja, Londrina, Paraná, Brazil (Table I). Culture stocks were maintained at $5^{\circ} \mathrm{C}$ in amber flasks with Basal Medium. Complete Medium (CM) and Basal Medium (BM) have previously been described by CastroPrado et al. (2007).

TABLE I

Origin of Brazilian C. truncatum isolates.

\begin{tabular}{lccc}
\hline Isolate & Strain & Area of origin & State \\
\hline A & 52192 & Londrina & Paraná \\
B & 0205 & Londrina & Paraná \\
C & 33104 & Londrina & Paraná \\
D & $28 . \mathrm{I}$ & Londrina & Paraná \\
E & 8 & Nova Ponte & Minas Gerais \\
F & 10.3 .2 & Taquarituba & São Paulo \\
G & 19 & Guairá & São Paulo \\
H & 17 & Bom Jesus & Goiás \\
I & 28.1 .1 & Rondonópolis & Mato Grosso \\
\hline
\end{tabular}

Isolation of nit mutants

Mycelium plugs, $5 \mathrm{~mm}$ in diameter, were removed from the periphery of $C$. truncatum colonies cultivated in $\mathrm{CM}$ and transferred to Petri plates with $\mathrm{BM}+\mathrm{NaNO}_{3}(0.2 \%)+$ 
$\mathrm{KClO}_{3}(3.6 \%)$. Plates were incubated at $22^{\circ} \mathrm{C}$ for 14 days. Mutants that produced poor growth colonies in the presence of potassium chlorate, or rather, without dense aerial mycelium, were classified as unable to use nitrate as a nitrogen source (nit). In order to determine the phenotypes of nit mutants, they were transferred to Petri plates with BM, supplemented with different nitrogen sources: sodium nitrate $(0.2 \%)$, potassium nitrite $(0.085 \%)$, hypoxanthine $(0.01 \%)$ and ammonium tartrate $(0.092 \%)$. Plates were incubated at $22^{\circ} \mathrm{C}$ for 10 days, and nit mutants were characterized into two distinct phenotypic classes: nitl (nitrate nonutilizing), and NitM (hypoxanthine and nitrate non-utilizing) (Klittich and Leslie, 1988).

\section{Hyphal anastomoses}

Complementary nit mutants from vegetative compatible isolates were paired in all possible combinations to determine their capacity for anastomosis. Mycelium plugs of nit mutants were placed $0.5 \mathrm{~cm}$ from each other on sterilized microscope slides covered with a thin layer of $\mathrm{BM}+\mathrm{NaNO}_{3}$. Slides were then placed in Petri plates containing the same medium. The plates were incubated at $22^{\circ} \mathrm{C}$ for 5 days. The mycelium plugs were then removed from the slides; the newly grown hyphae were stained with cotton blue in lactophenol, coverslipped and examined under a light microscope (Fig. 1A).

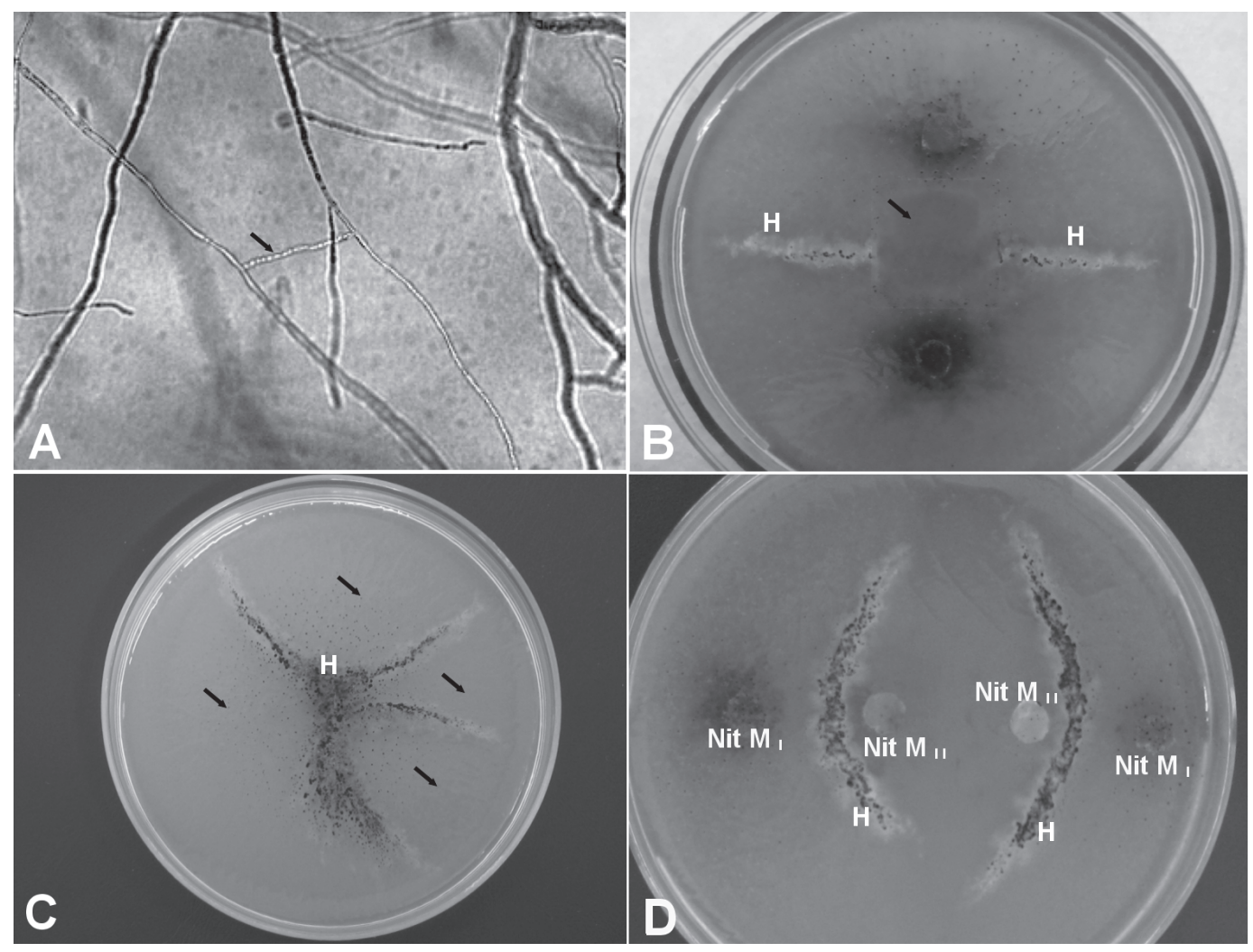

Figure 1: Pairing of nit mutants of Brazilian C. truncatum isolates. (A) Hyphae anastomosis (arrow) between nit mutants H.4 (nit1) and G.13 (NitM) from VCG-5. (B) Pairing between nit mutants H.4 (nit1) and G.13 (NitM) separated by a dialysis membrane. Heterokaryons (H) did not occur beneath the dialysis membrane (arrow), which impairs direct contact between the strains'mycelia. (C) Heterokaryotic colony, formed between H.4 and G.13 nit mutants, shows mitotic segregation of nit paternal mutants (arrows). (D) Heterokaryons (H) formed between NitM mutants of isolate G: G.13 (NitMI), G.49 (NitMII), G.51 (NitMII), and G.13 (NitMI). Heterokaryons did not occur between the two NitMII mutants, G.49 and G.51. 


\section{Obtaining heterokaryons}

Mycelium plugs (5mm) of nit mutant originating from the same and different wild isolates were paired equidistantly apart (approximately $1.0 \mathrm{~cm}$ ) in Petri plates containing $\mathrm{BM}+\mathrm{NaNO}_{3}$. Plates were incubated at $22^{\circ} \mathrm{C}$ for 12 to 30 days and then examined for heterokaryotic growth, in the contact area of the paired colonies, and for vegetative complementation group (VCG).

\section{Genetic complementation tests among NitM mutants}

NitM mutants were assessed by their ability to complement among themselves by pairing each NitM mutant equidistantly apart (approximately $1 \mathrm{~cm}$ ) from each other in $\mathrm{BM}+\mathrm{NaNO}_{3}$. Plates were incubated at $22^{\circ} \mathrm{C}$ for 12 to 30 days. NitM mutants that did not form heterokaryotic growth in the contact area of the mutant colonies were considered to belong to the same genetic complementation group (GCG).

\section{Cross-feeding test}

Two agar blocks cut from the growing edge colonies of two complementary nit mutants were placed on opposite sides, approximately $5 \mathrm{~cm}$ apart, on Petri plates containing $\mathrm{BM}+\mathrm{NaNO}_{3}$. A permeable cellulose dialysis membrane, which restricts physical contact between hyphae, was placed between the two colonies at the interaction zone. Plates were incubated at $22^{\circ} \mathrm{C}$ for 15 days and then examined for heterokaryotic growth (Fig. 1B).

\section{Isolation of parasexual segregants}

Heterokaryotic mycelium plugs $(5 \mathrm{~mm})$ were transferred to plates containing BM + $\mathrm{NaNO}_{3}$. Two methods were used to detect parasexual segregants (or sectors): (1) isolation of sectors showing nit phenotype, directly from the heterokaryotic colonies (Fig. 1C), and (2) suspensions of conidia obtained from heterokaryons colonies growing on $\mathrm{BM}+\mathrm{NaNO}_{3}$. Aliquots of these suspensions were grown in $\mathrm{BM}+\mathrm{NaNO}_{3}$ to recover parasexual segregants. Mycelium plugs $(5 \mathrm{~mm})$ of parasexual segregants were later transferred to BM supplemented with different nitrogen sources for phenotypic characterization.

\section{Genomic DNA extraction}

Pure cultures of $C$. truncatum wild isolates and nit mutants were grown in CM for 5 days at $25^{\circ} \mathrm{C}$. Mycelia were harvested by filtration (Whatman grade 1 filter paper) and ground to a fine powder in liquid nitrogen for DNA extraction, as described by Loudon et al. (1993).

\section{RAPD assay}

RAPD reactions were performed using five primers (Operon Technologies, USA): OPA-11 (CAATCGCCGT); OPA-18 (AGGTGACCGT), OPC-08 (TGGACCGG TG); OPF-05 (CCGAATTCCC); and OPW06 (AGGCCCGCTG) to assess the genetic diversity existing in soybean-originating $C$. truncatum isolates and to detect genetic changes in nit mutants derived from $C$. truncatum wild isolates. RAPD amplifications were carried out in a total volume of $25 \mu \mathrm{L}$ containing $10 \mathrm{mM}$ Tris$\mathrm{HCl}, 50 \mathrm{mM} \mathrm{KCl}, 3 \mathrm{mM} \mathrm{MgCl} 2,0.2 \mathrm{mM}$ of each deoxy-nucleotide triphosphate, $10 \mu \mathrm{M}$ of a single primer, $1.5 \mathrm{U}$ Taq DNA polymerase (Invitrogen), and $15 \mathrm{ng}$ of genomic DNA. Temperature cycling conditions were: initial denaturation at $94^{\circ} \mathrm{C}$ for $5 \mathrm{~min}, 34$ cycles of $94^{\circ} \mathrm{C}$ for 1 $\min , 35^{\circ} \mathrm{C}$ for $1 \mathrm{~min}$, and $72^{\circ} \mathrm{C}$ for $2 \mathrm{~min}$, and final extension at $72^{\circ} \mathrm{C}$ for $5 \mathrm{~min}$. All amplified DNA products were resolved by electrophoresis on polyacrilamide gel $(4.5 \%)$ in TBE $1 \mathrm{X}(45 \mathrm{mM}$ Tris Borate and $1 \mathrm{mM}$ EDTA) buffer, silver stained as described by Oliveira et al. (1997) and photographed. All experiments were repeated at least twice.

\section{$R A P D$ product scoring and data analysis}

DNA bands obtained for each $C$. truncatum wild isolate were scored manually and analyzed as polymorphic and monomorphic bands. Data were compiled as a binary $0 / 1$ 
matrix by presence (1) or absence (0) of a band at a particular position. The genetic similarities among individuals were estimated by using Jaccard coefficients. Dendrograms were produced by cluster analysis using the unweighted pair-grouped method by arithmetic average (UPGMA).

\section{RESULTS}

Isolation of nit mutants and VCG characterization

Nitrate non-utilizing mutants from the wild isolates $\mathrm{A}$ to $\mathrm{I}$ were obtained in $\mathrm{BM}+$ $\mathrm{NaNO}_{3}+\mathrm{KClO}_{3}$. Mutants were morphologically characterized by the production of thin expansive colonies on $\mathrm{BM}$ containing only nitrate as a nitrogen source. Mutants could be divided in two phenotypic classes that probably represent mutations in the nitrate reductase structural locus (nit1) and in loci codifying the cofactor containing molybdenum necessary for nitrate reductase activity (NitM). For each of the nine $C$. truncatum wild isolates, up to 30 distinctive nit mutants were recovered, with nitl mutants as the predominant phenotypic class (Table II).

NitM and nitl mutants from the same isolate were paired on $\mathrm{BM}+\mathrm{NaNO}_{3}$ to determine whether the wild isolates were vegetatively self-compatible. Eight of the nine isolates proved to be self-compatible due to the formation of dense heterokaryons. However, no intra- or interisolate complementation occurred for the isolate A when its complementary nit mutants were paired with one another or with distinct nit mutants of other isolates. Thus, isolate A could not be classified in the vegetative complementation groups.

By pairing nitl and nitM mutants of isolates $\mathrm{B}$ to $\mathrm{I}$ in $\mathrm{BM}+\mathrm{NaNO}_{3}$, five distinct vegetative compatibility groups (VCG) were identified: VCG-1 comprised isolates $\mathrm{C}, \mathrm{F}$ and $\mathrm{I}$; VCG-2 comprised isolate $\mathrm{B}$; VCG-3 formed by isolate D; VCG-4 included isolate $\mathrm{E}$, whereas isolates $\mathrm{G}$ and $\mathrm{H}$ were classified into VCG-5. Isolates from the same VCG, such as isolates C, F and I from VCG-1, and isolates $\mathrm{G}$ and $\mathrm{H}$ from VCG-5, carried out anastomosis among themselves (Table II, Fig. 1A).

Pairing of nit mutants belonging to the same VCG showed no heterokaryotic growth in $\mathrm{BM}+\mathrm{NaNO}_{3}$ when the paired mutants were separated by a dialysis membrane (Fig. 1B). Results demonstrate the need for physical contact among mutant hyphae (anastomosis) for heterokaryon formation. Furthermore, heterokaryotic colonies growing on plates containing $\mathrm{BM}$ $+\mathrm{NaNO}_{3}$ gave rise spontaneously to auxotrophic sectors (parasexual segregants)

TABLE II

Frequency of nit mutants, vegetative compatibility groups (VCG) and genetic complementation groups (GCG) of Brazilian C. truncatum isolates A to I.

\begin{tabular}{lcccc}
\hline Isolates & \multicolumn{2}{c}{ nit mutants (\%) } & nit $M$ & VCG \\
\cline { 2 - 4 } & nit1 & 14 & nd $^{2}$ & GCG \\
\hline $\mathrm{A}^{1}$ & 86 & 06 & 2 & nd $^{2}$ \\
B & 94 & 13 & 1 & B-I to B-III \\
C & 87 & 13 & 3 & C-I to C-III \\
D & 87 & 77 & 4 & D-I to D-V \\
E & 23 & 31 & 1 & E-I, E-II \\
F & 69 & 07 & 5 & F-I to F-III \\
G & 93 & 15 & 5 & G-I, G-II \\
H & 85 & 50 & 1 & H-I to H-III \\
I & 50 & & & I-I, I-II \\
\hline
\end{tabular}

${ }^{1}$ self-incompatible; ${ }^{2}$ not determined. 
that exhibited the parental phenotypes of the crossed mutants (Fig. 1C). The relative proportions of parental types recovered from heterokaryons, however, varied from heterokaryons to heterokaryons (Table III).

\section{Genetic complementation groups (GCG) among NitM mutants}

NitM mutants from the same isolate were paired in $\mathrm{BM}+\mathrm{NaNO}_{3}$ to determine how many loci control the production of the molybdenum-containing cofactor in the Brazilian C. truncatum isolates. The inability of different NitM mutants to form heterokaryon among themselves classifies these mutants as member of the same genetic complementation group (GCG) (Fig. 1D). On the other hand, the heterokaryon formation between paired NitM mutants indicates intergenic complementation and classifies these mutants as members of distinct GCGs. For instance, mutants NitM-I from isolate B formed heterokaryons with two classes of NitM mutants, NitM-II and NitM-III, but not with other NitM-I mutant from the same isolate. Since NitM-II and NitM-III mutants also formed heterokaryons among themselves, three GCGs (I, II and III) could be identified in the isolate B (Table IV). Pairings also identified two GCGs (I and II) in isolates E, G, and I; three GCGs (I to III) in isolates $\mathrm{C}, \mathrm{F}$ and $\mathrm{H}$; and five GCGs (I to V) in isolate D (Table IV). The selfincompatible isolate was not included in these analyses.

\section{RAPD analysis of wild isolates}

The five primers generated reproducible amplifications products showing polymorphic profiles among the nine $C$. truncatum isolates. A total of 101 bands were scored, of which $86(85.15 \%)$ were polymorphic. Figure 2 gives an example of the amplifications profiles observed when using random primers. RAPD profiles using primer OPA-11 and OPA-18 were similar for the most of the isolates, except for isolate E (Fig. 2A and B). In fact, a band with approximately 1000 bp (Fig. 2A) has been shown in all isolates, except in isolate E. Contrastingly, bands with approximately $450 \mathrm{bp}$ and $650 \mathrm{bp}$ (Fig. 2B) were shown only by isolate E. Additionally, similar RAPD profiles were observed among the self-incompatible isolate $\mathrm{A}$ and the wild $\mathrm{C}$ isolate (Fig. 2 A and B).

\section{TABLE III}

Recovery of parental phenotypes from heterokaryons formed with Brazilian C. truncatum nit mutants

\begin{tabular}{|c|c|c|c|c|}
\hline Auxotrophic pairing & & henotypes o & al segregant & \\
\hline Paternal $1^{1}$ & Paternal $2^{1}$ & Paternal 1 & Paternal 2 & Total $^{2}$ \\
\hline C.16 $\left(\right.$ nit $\left._{I I}\right) /$ & C.17 (nit1) $)^{3}$ & 74 & 47 & 121 \\
\hline C.16 $\left(\right.$ nit $\left._{I I}\right) /$ & C. $37(\text { nitl })^{3}$ & 16 & 14 & 30 \\
\hline C.16 $\left(\right.$ nit $\left._{I I}\right) /$ & C. $10(\text { nit } 1)^{3}$ & 13 & 24 & 37 \\
\hline B.15 $\left(\right.$ nitM $\left._{1}\right) /$ & B.12(nit 1$)^{3}$ & 05 & 15 & 20 \\
\hline B.15 $\left(\right.$ nit $\left._{1}\right) /$ & B.18 (nit1 $)^{3}$ & 03 & 32 & 35 \\
\hline B.15 (nit $\left.M_{1}\right) /$ & B. $26(\text { nit } 1)^{3}$ & 16 & 51 & 67 \\
\hline C.16 $\left(\right.$ nit $\left._{I I}\right) /$ & I.37 $(\text { nit } 1)^{4}$ & 27 & 0 & 27 \\
\hline I.50 $\left(\right.$ nitM $\left._{I I}\right) /$ & C. $17(\text { nitl })^{4}$ & 12 & 12 & 24 \\
\hline F.36 (nitM $\left.M_{I I I}\right) /$ & C.37 (nit1) ${ }^{4}$ & 12 & 30 & 42 \\
\hline C.16 $\left(\right.$ nitM $\left._{I I}\right) /$ & F.19(nit 1$)^{4}$ & 69 & 02 & 71 \\
\hline G.13 $\left(\right.$ nitM $\left._{1}\right) /$ & H.4 (nitl) $)^{4}$ & 14 & 36 & 50 \\
\hline H.33 (nitM 1 III $/$ & $\mathrm{G} .39(\text { nitl })^{4}$ & 60 & 03 & 63 \\
\hline
\end{tabular}

${ }^{1}$ Strains designated by parent and isolation number, e.g. B.15 is the fifteenth nit mutant from isolate B; ${ }^{2}$ Total number of segregants; ${ }^{3}$ intrastrain pairing of auxotrophic mutants; ${ }^{4}$ interstrain pairing of auxotrophic mutants. 


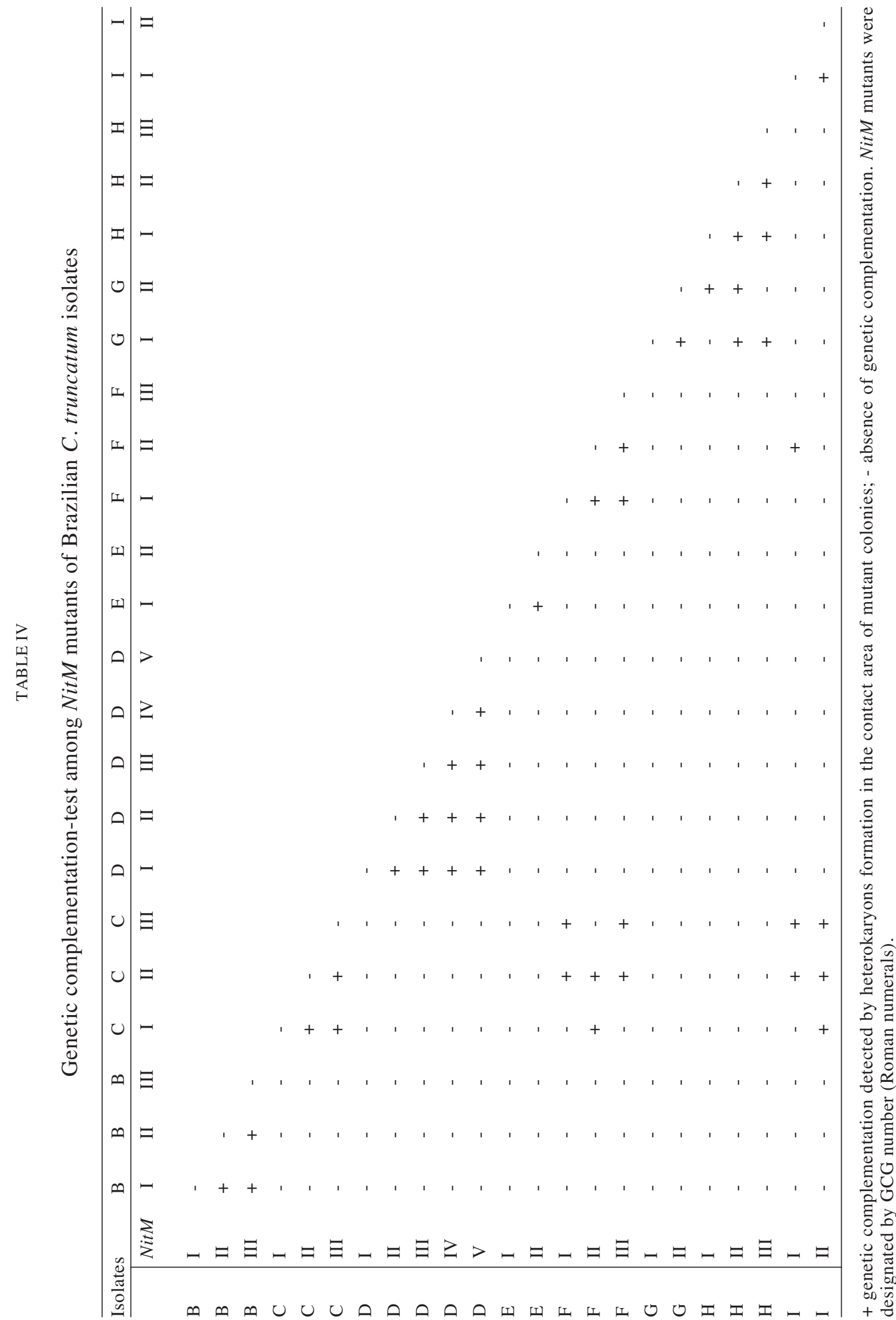


The genetic similarity among $C$. truncatum isolates ranged from 0.331 (isolate $\mathrm{E}$ ) to 0.882 (isolates $\mathrm{B}$ and $\mathrm{F}$ ). Cluster analysis identified three different RAPD groups. Group I is composed of isolates $\mathrm{A}$ and $\mathrm{C}$, which present a degree of similarity of 0.658 . In group II, two subgroups had been identified, namely, subgroup IIa (isolates B, D and F) and subgroup $\mathrm{IIb}$ (isolates $\mathrm{G}, \mathrm{H}$ and $\mathrm{I}$ ), with similarity coefficient of 0.821 and 0.781 , respectively. Group III is formed only by isolate $\mathrm{E}$, which showed the lowest similarity coefficient (0.331) (Fig. 3).

\section{RAPD analysis of nit mutants}

Genetic polymorfism could be identified between the wild isolate $\mathrm{C}$ and their auxotrophic mutants C.17 (nit1), C.16 (NitM), C.60 (NitM), and C.62 (NitM). In the RAPD analysis obtained with primer OPA-11, a band of 490 bp was amplified from the wild $\mathrm{C}$ isolate and from C.17 (nit1), C.60 (NitM), and C.62 (NitM) mutants, but it was not observed in the C.16 NitM mutant (Fig. 4A). In the RAPD profiles performed with primer OPA-18, polymorphic bands, with approximately 180

A)

B)

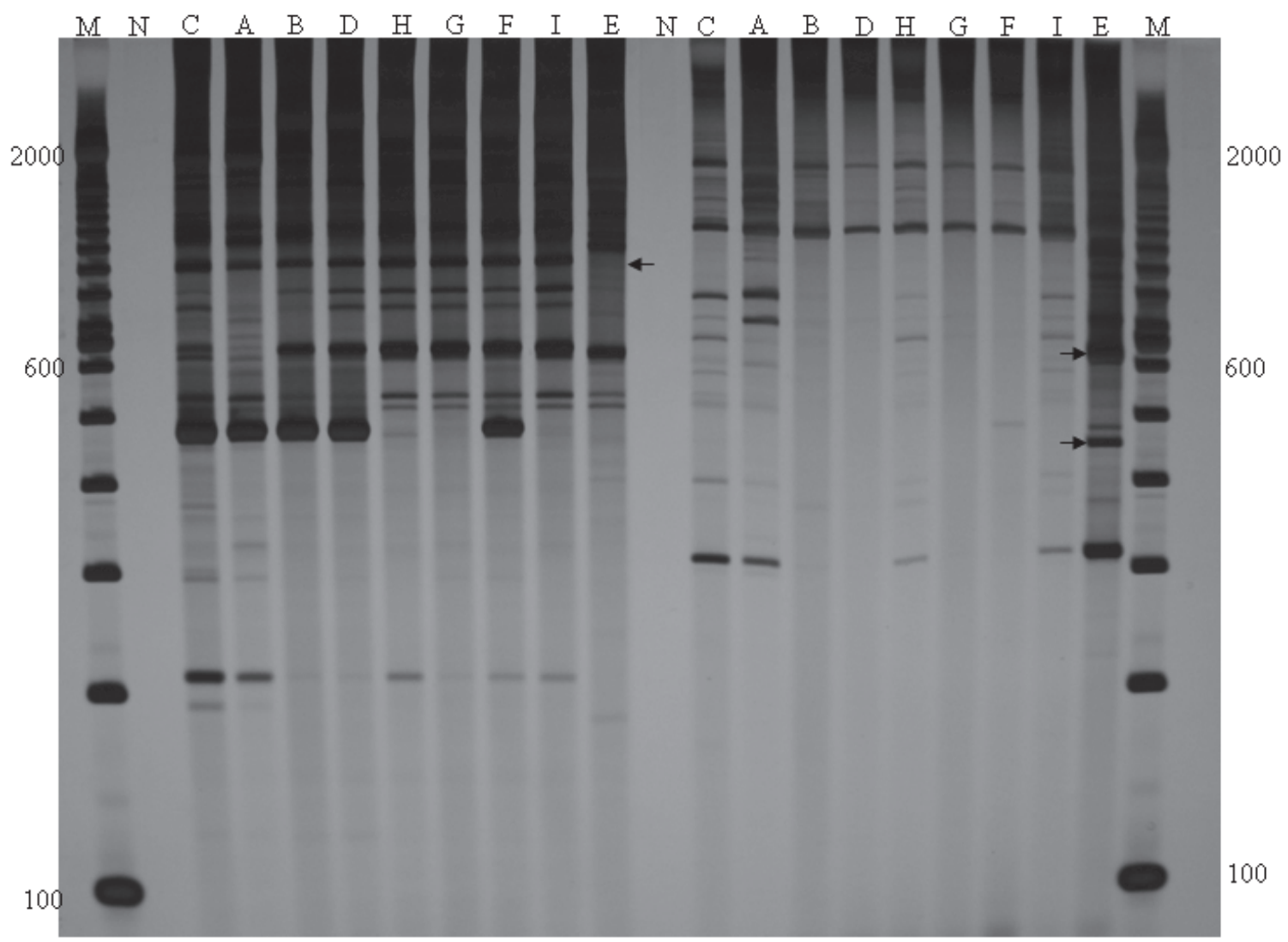

Figure 2: Amplified products of nine wild isolates of $C$. truncatum from different Brazilian states in polyacrilamide gel. RAPD profiles generated by the primer OPA-11 (A) and primer OPA-18 (B). Columns $\mathrm{C}$ to $\mathrm{D}$ represent isolates from the state of Paraná; column $\mathrm{H}$, from the state of Goiás; columns G and F, from the state of São Paulo; columns I and E, from the state of Mato Grosso and Minas Gerais, respectively; columns $\mathrm{M}$ and $\mathrm{N}$, molecular markers and negative control, respectively. Arrows indicate some polymorphic bands. 
bp, 220 bp, 300 bp, 350 bp, 400 bp and $1200 \mathrm{bp}$, were amplified only from the C.17 (nit1) mutant. Furthermore, a band with approximately $350 \mathrm{bp}$ was amplified from C.62 (NitM) and C.17 (nit1) mutants; however, it was not reported in the C.16 and C.60 (NitM) mutants (Fig. 4B).

\section{DISCUSSION}

Nitrate non-utilizing mutations are auxotrophic markers useful for triggering heterokaryon formation and for testing fungal isolates for vegetative compatibility. Nit mutants were relatively easy to recover from $C$. truncatum soybean-isolates, allowing the assessing of most of the isolates for vegetative compatibility. Complementation tests among nit mutants showed that vegetative incompatibility barriers were clearly present among soybean-infecting isolates of $C$. truncatum. Three out of the five VCGs, designated VCG-2, VCG-3 and VCG-4, contained only one isolate in each group, whereas VCG-1 and VCG-5 contained three isolates and two isolates, respectively. Only one of the examined isolates, named isolate $\mathrm{A}$, failed to undergo both self and non-self hyphal fusions (Table II). Self-incompatible phenotype has already been reported in Gibberella fujikuroi, probably controlled by a single segregating gene ( $h s i-1$ ) (Correl et al., 1989). Since inter-isolate complementation could not be demonstrated using genetically complementary nit mutants of isolate $\mathrm{A}$, such self-incompatible isolate was not classified for vegetative compatibility group. In spite of this fact, isolate A showed several RAPD markers in common with the isolate $\mathrm{C}$ from VCG-1 (Table II, Figs. 2 and 3).

The absence of heterokaryon formation, when physical contact between the crossed isolates was impaired, indicated that heterokaryon formation was due to direct hyphal fusion and not to cross feeding. Additionally, the recovery of mitotic sectors (or segregants) from the heterokaryon, which exhibited the nit
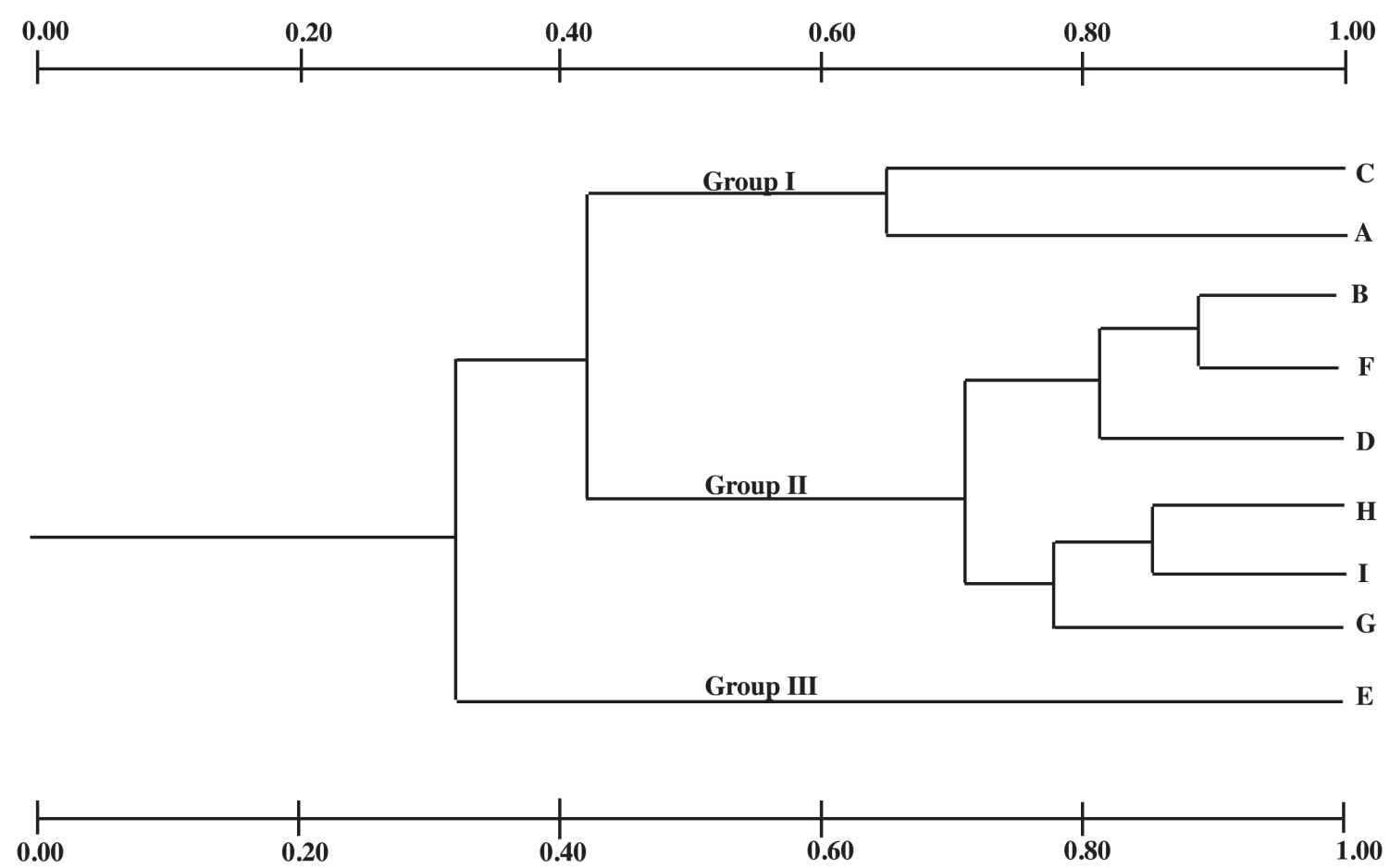

Figure 3: Dendrogram showing genetic similarity between isolates of C. truncatum from different Brazilian states based on RAPD profiles. 
phenotypes of the paired mutants, indicates that the prototrophic growth of the heterokaryon was not a reversion to prototrophy but a consequence of true heterokaryon formation (Fig. 1B and D, Tables II and III).
Mutants NitM from the examined isolates showed intergenic complementation patterns among themselves, suggesting the existence of multiple loci controlling this phenotype in C. truncatum. Similar results have also

A)

B)

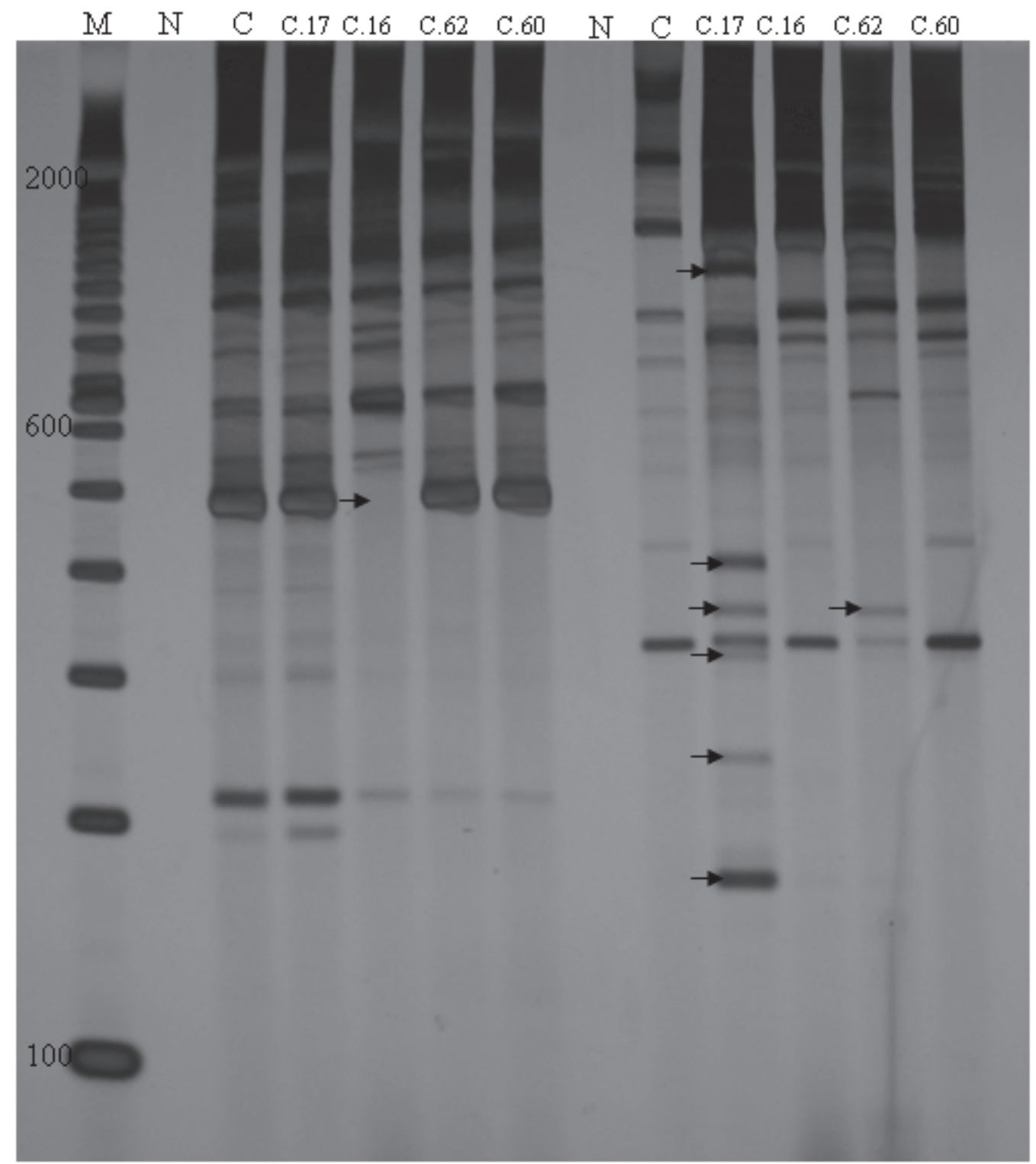

Figure 4: Polyacrilamide gel showing RAPD profile of $C$. truncatum from wild $C$ isolate and its nit mutants. Amplified products were generated by primer OPA-11 (A) and primer OPA-18 (B). Column C, wild C isolate; column C.17, nit1 mutant; columns C.16 to C.60, NitM mutants; columns $\mathrm{M}$ and $\mathrm{N}$, molecular markers and negative control, respectively. Arrows indicate some polymorphic bands. 
been reported in other Colletotrichum species, such as $C$. lindemuthianum and $C$. sublineolum (Castro-Prado et al., 2007; Fávaro et al., 2007). Furthermore, genetic polymorphism was detected by RAPD analysis with primer OPA-18 among NitM mutants belonging to the same (C.16 and C.62) and different (C.60) GCGs (Fig. 4B).

RAPD profiles obtained with primers OPA-18 and OPA-11 were able to differentiate the wild $\mathrm{C}$ isolate and their auxotrophic C.17 (nit1), C.16, C.60 and C.62 (NitM) mutants, showing that differences at the DNA level could be detected among phenotypically distinct strains through the molecular method utilized. RAPD markers showed polymorphic profiles among the wild isolates, while a degree of similarity of 0.724 was observed among isolates from RAPD group II (isolates $\mathrm{B}, \mathrm{D}, \mathrm{F}, \mathrm{G}, \mathrm{H}$, and I).

Since the vegetative compatibility tests and the RAPD analysis showed that $C$. truncatum isolates could not be clustered according to their geographic origins, the occurrence of free interchange of $C$. truncatum infected seeds among the Brazilian States has been suggested. Isolates $\mathrm{C}, \mathrm{F}$ and $\mathrm{I}$, from different geographical areas (states of Paraná, São Paulo, and Mato Grosso, respectively), were included into a single VCG (VCG-1) and isolates $F$ and $G$, from the state of São Paulo, were classified into distinct VCGs, albeit in the same RAPD group II (Table II, Fig. 3). On the other hand, isolates B, D, F, $\mathrm{G}, \mathrm{H}$ and $\mathrm{I}$, included in the same RAPD group II, could be separated into four different VCGs (Table II, Fig. 3). Results demonstrate the potential of the VCG analysis to differentiate $C$. truncatum isolates genotypically similar when compared by RAPD method. Similar results were obtained in the characterization of $C$. acutatum isolates from Israel and Fusarium graminearum isolates from Brazil (Freeman et al., 2000; Busso et al., 2007). Although a correlation between VCG and RAPD analysis has not been observed in present study, isolates $\mathrm{G}$ and $\mathrm{H}$, which showed a degree of similarity of 0.816 by RAPD analysis, were also grouped in the same VCG (Table II, Fig 3).

The genetic variability resulting from the parasexual recombination in fungi was first described by Pontecorvo et al. (1953) in the ascomycete Aspergillus nidulans. Subsequently, the term parasexuality was proposed by Pontecorvo (1956) to define processes that result in obtaining recombinant strains without passing through the sexual cycle. The parasexual cycle starts with the formation of the heterokaryon, governed by a rigid genetic system, where vegetatively compatible strains are defined as members of a same VCG (Leslie, 1993; Saupe, 2000). The coexistence of two vegetatively compatible isolates in the same host might lead towards heterokaryon formation. The fusion of two distinct haploid nuclei may then occur inside the heterokaryotic hyphal, originating a diploid nucleus, potentially capable of undergoing mitotic crossingover, and originating parasexual recombinants, with greater or lesser virulence.

Thus, the parasexual process might be an important factor to increase the genetic variability in $C$. truncatum soybean isolates. Despite the occurrence of parasexual recombination in some Colletotrichum species (Chacko et al., 1994; Souza-Paccola et al., 2003), further evidence for asexual gene exchange in $C$. truncatum is required and is dependent on the isolation of stable mitotic recombinants following intrastrain or interstrain pairing of auxotrophic mutants.

\section{REFERENCES}

ALMEIDA AMR, FERREIRA LP, YORINORI JT, SILVA JFV, HENNING AA, GODOY CV, COSTAMILAN LM, MEYER MC. (2005) Doenças da soja (Glycine $\max$ L.). In: KIMATI H, AMORIM L, BERGAMINFILHO A, CAMARGO LEA, REZENDE JAM (eds) Manual de Fitopatologia. $4^{\text {th }}$ ed. São Paulo: Editora Agronômica Ceres, v.2, pp.569-588.

ANDERSON KL, BUCHWALDT L, SILLERO J, GOSSEN BD (2000) Host range of Colletotrichum truncatum from lentil. Can J Plant Pathol 22: 180.

BOYETTE CD (1991) Host range and virulence of Colletotrichum truncatum, a potential mycoherbicide for hemp sesbania (Sesbania exaltata). Plant Disease 75: 62-64. 
BUSSO C, KANESHIMA EN, FRANCO FA, QUEROL CB AND CASTRO-PRADO MAA (2007) Vegetative compatibility and molecular characterization of Fusarium graminearum isolates from the state of Paraná, Brazil. Rev Ciência Rural 37: 1813-1816.

CASELA CR, FREDERIKSEN RA (1994) Pathogenic variability in monoconidial isolates of the sorghum anthracnose fungus Colletotrichum graminicola from single lesions and from monococidial cultures. Fitopatol Bras 19: 149-153.

CASTRO-PRADO MAA, QUEROL CB, SANT' ANNA JR, MIYAMOTO CT, FRANCO CCS, MANGOLIN CA, MACHADO MFP (2007) Vegetative compatibility and parasexual segregation in Colletotrichum lindemuthianum, a fungal pathogen of the common bean. Gen Mol Res 6: 634-642.

CATEN CE (1981) Parasexual processes in fungi. In: GULL K, OLIVER G (eds) The Fungal Nucleus. Cambridge, UK: Cambridge University Press, 191-214.

CHACKO RJ, WEIDEMANN GJ, TEBEEST DO, CORRELL JC (1994) The use of vegetative compatibility and heterokaryosis to determine potential asexual gene exchange in Colletotrichum gloeosporioides. Biol Control 4: 382-389.

CHEN LS, CHU C, LIU CD, CHEN RS, TSAY JG (2006) PCR-based Detection and Differentiation of Anthracnose Pathogens, Colletotrichum gloeosporioides and $C$. truncatum, from Vegetable Soybean in Taiwan. J Phytopathol 154: 654-662.

CORRELL JC, KLITTICH CJR, LESLIE JF (1989) Heterokaryon self-incompatibility in Gibberella fujikuroi (Fusarium moniliforme). Mycol Res 93: 2127.

CURRY KJ, BAIRD RE (2004) Ascomycota: The filamentous fungi forming Perithecia, Apothecia, and Ascostromata. In: TRIGIANO RN, WINDHAM MT, WINDHAM AS (eds) Plant pathology, concepts and laboratory exercises. Florida, CRC press, pp. 127-132.

FAVARO LCL, ARAÚJO WL, SOUZA-PACCOLA EA, AZEVEDO JL, PACCOLA-MEIRELLES LD (2007) Colletotrichum sublineolum genetic instability assessed by mutants resistant to chlorate. Mycol Res 111: 93105

FORD R, BANNIZA S, PHOTITA W, TAYLOR PWJ (2004) Morphological and molecular discrimination of
Colletotrichum truncatum causing anthracnose on lentil in Canada. Australian Plan Pathology 33: 559-569.

FREEMAN S, MINZ D, JURKEVITCH E, MAYMON M, SHABI E (2000) Molecular analyses of Colletotrichum species from almond and other fruits. Phytopathol 90: 608-614.

KLITTICH CJR, LESLIE JF (1988) Nitrate reduction mutants of Fusarium moniliforme (Gibberella fujikuroi). Genetics 118: 417-423.

LESLIE JF (1993) Fungal Vegetative Compatibility. Annu Rev Phytopathol 31: 127-150.

LOUDON KW, BURNIE JP, COKE AP, MATTHEWS RC (1993). Application of polymerase chain reaction to fingerprint Aspergillus fumigatus by random amplification of polymorphic DNA. J Clin Microbiol 31: 1117-1121.

OLIVEIRA RP, MACEDO AM, CHIARI E \& PENA SDJ (1997) An alternative approach to evaluating the intraspecific genetic variability of parasites. Parasitol. Today 13 (5): 196-200.

PONTECORVO G (1956) The parasexual cycle in fungi. Annu Rev Microbiol 10: 393-400.

PONTECORVO G, ROPER JA, FORBES E (1953) Genetic recombination without sexual reproduction in Aspergillus niger. J Gen Microbiol 8: 198-210.

SAUPE SJ (2000) Molecular genetics of heterokaryon incompatibility in filamentous ascomycetes. Microbiol Mol Biol Rev 64: 489-502.

SHARMA R (2007) Genetic differentiation of host limited forms of

Colletotricum truncatum from northwestern Himalayas. Arch Phytopathol Plant Protect, DOI: 10. 1080/ 03235400701543848.

SOUZA-PACCOLA EA, FÁVARO LCL, CASELA CR, PACCOLA-MEIRELLES LD (2003) Genetic recombination in Colletotrichum sublineolum. J Phytopathol 151: 329-334.

WEIDEMANN GJ, TEBEEST TO, CARTWRIGHT RD (1988) Host specificity of Colletotrichum gloeosporioides $\mathrm{f}$. sp. aeschynoemene and C.truncatum in the Leguminosae. Phytopathol 78: 986-990.

ZEIGLER RS, SCOTT RP, LEUNG H, BORDEOS AA, KUMAR J, NELSON RJ (1997) Evidence of parasexual exchange of DNA in the rice blast fungus challenges its exclusive clonality. Phytopathol 87: 284-294. 